\title{
Özel Eğitim İçin Etkileşimli Kavranabilir Nesne Tabanlı Eğitsel Mobil Uygulama Kullanımı Konusunda Öğretmen Görüşlerinin Analizi
}

\author{
An Analysis of Teachers' Opinions on Using Interactive Tangible \\ Objects Based Educational Mobile Application for Special \\ Education
}

\author{
Elif POLAT*, Kürşat ÇAĞILTAY**
}

\begin{abstract}
Öz: Çalışmanın amacı, özel öğrenme güçlüğü yaşayan ilköğretim 6-8. sınıf öğrencileri için geliştirilen elle kavranabilir etkileşimli nesnelerle çalışan eğitsel mobil uygulamanın öğretmenler tarafından kullanım durumunun incelenmesidir. Araştırma kapsamında, öğretmenlerin bu uygulamayı kullanım durumlarını incelemek için öğretmene -öncesinde herhangi bir eğitim verilmeksizin- elle kavranabilir etkileşimli nesnelerle çalışan eğitsel uygulama verilerek bunu öğrenciye uygulaması istenmiş̧ir. Asıl uygulama öncesinde pilot bir uygulama gerçekleștirilmiştir. Her iki uygulama birer özel eğitim öğretmeni ve özel öğrenme güçlüğü yaşayan birer 6 . Sınıf öğrencisi ile yürütülmüştür. Çalışmada nitel araştırma desenlerinden araştırmanın doğasına uygun olan durum çalışması kullanılmıştır. Öğretmen uygulamalarının video kamera kaydı alınmıştır. Bunun yanı sıra özel eğitim öğretmenleriyle görüşme yapılmıştır. Araştırmada veri toplama aracı olarak yarı yapılandırılmış görüşme formu kullanılmıștır. Video kayıtları ve görüşmeler analiz edildiğinde, özel eğitim öğretmenlerinin daha önce hiç kullanmadıkları halde, elle kavranabilir etkileşimli nesnelerle çalışan eğitsel uygulamayı genel olarak kolay bir biçimde kullanabildikleri ortaya çıkmıştır. Öğretmenler elle kavranabilir etkileşimli nesnelerle çalışan eğitsel uygulamayı kendi derslerinde kullanmak istediklerini belirtmişlerdir. Ortaya çıkan sonuçlar, özel öğrenme güçlüğü yaşayan öğrenciler için geliştirilecek öğretim uygulamaları için yol gösterici niteliktedir.

Anahtar Kelimeler: Özel öğrenme güçlüğü, etkileşimli mobil eğitsel uygulama, kavranabilir teknolojiler
\end{abstract}

\begin{abstract}
The main purpose of this study is to obtain the reflections of special education teachers after using the tangible mobile application by students with specific learning disabilities (SLD). Within the scope of the study, teachers were asked to use tangible mobile application on their students to determine whether it is easy to use or not. Teachers were not given any training before the implementations. After a pilot study had been conducted with a special education teacher and a student with SLD in 6th grade, the main study was held with a special education teacher and a student with SLD in 6th grade. In this study, the qualitative data collection techniques were employed to obtain the reflections of special education teachers after using the tangible mobile application on students with SLD. Case study was used. They were video-recorded. Semi-structured interviews were administered to two special education teachers. When video recordings and interviews were analyzed, special education teachers were able to use tangible mobile application easily without any experience. Special education teachers were willing to use of the tangible mobile applications their classes. The results of the study are also expected to be a guidance to develop educational applications for students with SLD.

Keywords: Specific learning disabilities, interactive educational mobile application, tangible technologies
\end{abstract}

\section{Giris}

Her birey gibi özel eğitime ihtiyacı olan bireylerin de kendilerine özgü özellikleri, ilgi ve yetenekleri, öğrenme ihtiyaçları ve hakları bulunmaktadır. MEB (2008) Özel Eğitim ve Rehabilitasyon Merkezi Özel Öğrenme Güçlüğü Destek Eğitim Programı'nda belirtildiği gibi bireyin ihtiyaçlarının karşılanmasında

\footnotetext{
*Arş. Gör. Dr., İstanbul Üniversitesi, Eğitim Fakültesi Bilgisayar ve Öğretim Teknolojileri Eğitimi Bölümü, İstanbul / TÜRKIYE, ORCID: 0000-0002-6086-9002, e-posta: elif.polat@istanbul.edu.tr

**Prof. Dr., Orta Doğu Teknik Üniversitesi, Eğitim Fakültesi Bilgisayar ve Öğretim Teknolojileri Eğitimi Bölümü, Ankara/ TÜRKIYE, ORCID: 0000-0003-1973-7056, e-posta: kursat@metu.edu.tr
} 
birinci etken bireyin ihtiyaç duyduğu eğitimin sağlanmasıdır. Eğitim sistemi içerisinde, artan ihtiyaçlarıyla birlikte özel öğrenme güçlüğü yaşayan çok sayıda öğrenci mevcuttur. Eğitim teknolojisi uygulamaları bu öğrencilerin ihtiyaçlarını karşılama potansiyeline sahip olabilir. Özel eğitimde eğitim teknolojisinin kullanımı, öğretici yazılımlar, simülasyon ve sanal ortamlar gibi öğrenme ortamları, tekrar alıştırma yazılımları, eğitsel oyunlar, değerlendirme ve yönetim araçları ve iletişim araçlarını içermektedir (Florian, 2004). Bu uygulamaların yanı sıra, tabletlerin elle kavranabilir nesnelerle beraber kullanılmasının özel öğrenme güçlügü yaşayan öğrencilerin öğrenme deneyimlerini zenginleştirme açısından önemli bir potansiyele sahip olduğu düşünülmektedir. Elle kavranabilir uygulamaların amacı fare, klavye, monitör gibi geleneksel giriş çıkış cihazlarını kullanmaksızın gerçeğe benzer nesnelerle fiziksel ve dijital ortamlar arasındaki etkileşimi sağlamaktır (Ullmer ve Ishii, 2000). Tuşlara basmak yerine fiziksel hareketler yoluyla bilgisayarla sağlanan etkileşim, bilgisayar arayüzünü gerçek dünyaya daha fazla yaklaştırmaktadır (Jacob ve diğerleri, 2008). Fishkin (2004) kavranabilir arayüz ve bilgisayar sistemi arasındaki etkileşimin adımlarını: 1- Bilgisayar sistemine fiziksel hareketler yoluyla bazı girdiler gönderilmesi, 2- Bilgisayar sistemi tarafından girdilerin işlenmesi, 3- Girdilerin dikkate alınarak kullanıcıya geri bildirim verilmesi şeklinde ifade etmiştir.

Kavranabilir teknolojilerin temel kullanım alanlarından birisi de eğitimdir. O'Malley ve Fraser (2004) kavranabilir teknolojilerin eğitim için, kendine has ve yenilikçi özellikleriyle, gelecek vadeden bir potansiyel ve kapasiteye sahip olduğunu vurgulamışlardır. Kavranabilir teknolojiler, fiziksel dünyayı arayüze taşıyarak öğrencilere yararlar sağlar ve bu şekilde eğitimde önemli bir yer tutar (Horn, Solovey, Crouser ve Jacob, 2009). Bu teknolojiler öğrencilerin gerçek dünyayı gerçek dünya içinde anlamalarına yardımcı olur (Antle, 2007). Bu teknolojiler bugün kullanılan öğretim teknolojilerinin değerini azaltmamaktadır. Ancak gerçek dünya nesneleriyle etkileşim sağlamak bilgisayar destekli eğitim uygulamaları için zordur. Sanal ve somut arasındaki yalıtımı azaltmak, öğretim tasarımcılarının bilgisayar destekli materyallerin ötesinde daha gerçekçi tasarım yapabilmeleri noktasında yeni kapılar açar (Eisenberg ve diğerleri, 2003).

Fiziksel etkinliklerin öğrenmede rol oynayabileceği söylenebilir. Öğrenmede kavranabilir teknolojilerin kullanılmasının yararlarından biri olarak Marshall (2007) ve O'Malley ve Fraser (2004) Piaget'ci Gelişim Teorisi'ne göre somut fiziksel nesneleri idare etmenin (kullanmanın), düşünme ve öğrenmeyi geliştirebileceğini vurgulamışlardır. Çoklu duyu olarak görsel, işitsel ve dokunsal duyuların bir arada kullanımı, öğrencilerin soyut problemlerdeki bilgiyi yapılandırmalarına yardım eder (Zuckerman, Arida ve Resnick, 2005). Çalışmalar, çocukların veya yetişkinlerin bilgileri sözel olarak ifade edemezken şaşırtıcı bir şekilde el, kol ve baş hareketleriyle fiziksel olarak ifade edebildiklerini göstermiştir (O'Malley ve Fraser, 2004). Kavranabilir teknolojiler, soyut bilgileri erişilebilir kılar (Shaer ve Hornecker, 2010).

Ayrıca bu teknolojiler, öğrenenlerin birbirleriyle işbirliği yapmasına izin verir. Marshall'ın (2007) ifadesine göre çok sayıda tasarım tabanlı araştırma, kavranabilir arayüzlerin işbirliği için uygunluğunu vurgulamaktadır. Kavranabilir teknoloji, öğrenciler tarafindan paylaşılabilen bir alanda işbirlikli etkileşimi sağlamaya yardım etmektedir (Horn ve diğerleri, 2009). Keay-Bright (2008) öğrenme güçlüklerinde bilgi ve iletişim teknolojileri kullanımının birçok pozitif sonucu olduğunu belirtmektedir. Ancak işbirlikli öğrenmenin yanı sıra yaratıcı ve esnek düşünmeyi sağlamaya yardım eden ve duyusal hareketlerin kullanıldığı teknolojilerin hala çok az sayıda olduğunu vurgulamıştır.

Özel eğitimi desteklemede kavranabilir teknolojiler son yıllarda kullanılmaya başlamıştır (Shaer ve Hornecker, 2010). Falcão ve Price (2010) bu teknolojilerin özel öğrenme güçlüğü yaşayan öğrencilere birden fazla duyuya dayalı etkileşim için firsatlar sunduğunu ifade etmektedirler. Kavranabilir teknolojiler özel eğitim için bilişsel, sosyal, dilsel öğrenme olanakları sağlayarak grafiksel kullanıcı arayüzünden daha zengin öğrenme ortamları sunmaktadır (Shaer ve Hornecker, 2010). Özel öğrenme güçlüğü (ÖÖG) yaşayan öğrencilerin öğrenmesini kolaylaştırmak için literatürde bazı öğretim strateji ve yöntemleri mevcuttur (çok duyuya dayalı yaklaşım (MEB, 2008) veya işbirlikli yaklaşım (Sucuoğlu ve Kargın, 2006). Kavranabilir teknolojiler bu veya benzer öğretim stratejilerini destekleme ihtimalini arttırmaktadır. Literatür ışığında, kavranabilir teknolojilerin kullanılması genel eğitimde olduğu kadar özel eğitimde de giderek daha önemli hale geldiği söylenebilir. Gelecek vadeden potansiyeli olmasına rağmen, uluslararası literatürde kavranabilir teknolojilerin özel öğrenme güçlüğü yaşayan öğrencilerde kullanımı ile ilgili sınırlı sayıda araştırma (Antle, Fan ve Cramer, 2015; Fan ve Antle, 2015; Fan, Antle ve Cramer, 2016; Fan, Antle, Hoskyn, Neustaedter ve Cramer, 2017; Linke, Kothe ve Alt, 2017; Pandey ve Srivastava, 2011a, 2011b) mevcuttur. Türkiye'de ise bu çalışmadan hedef 
kitle ve kullanılan teknoloji olarak farklılık gösterse de benzer olabilecek tek bir çalışmaya rastlanmıştır (Kara, 2015).

Linke ve diğerleri (2017), öğrencilerin okuma motivasyonlarını artırmak için karma bir öğrenme uygulaması (TaBooGa-kavranabilir kitap oyunu) geliştirmişlerdir. $\mathrm{Bu}$ çalışmada, e-kitapların kavranabilir nesnelerle geliştirilmesinin okuma motivasyonunu daha da arttırabildiği ortaya çıkmıştır. Özellikle, kitapta gezinmeyi sağlayan kavranabilir nesneler ve okuma görevini birleştiren mini oyunlar TaBooGa'ya yerleştirilmiştir. Araştırma sonuçları, yaklaşımın hem güçlü hem de zayıf okuyucular üzerindeki etkisini karşılaştırarak, 7-9 yaş arası 22 öğrenci arasındaki değerlendirme sonucunu ortaya koymaktadır. Sonuçlar, tablet ile birleştirilen kavranabilir nesnelerin hem zayıf hem de güçlü okuyucularda okuma motivasyonu kadar etkileşim ve okuyucuların davranışları üzerinde de olumlu bir etki göstermektedir.

Pandey ve Srivastava (2011a) 8-12 yaş aralığında disleksi yaşayan öğrencilere temel İngilizce kelimeleri hecelemeyi öğreten SpellBound isminde kavranabilir etkileşimli öğrenme yardım sistemini geliştirmişlerdir. Bu sistem, kavranabilir objeler kullanılarak etkinlik tabanlı bir prototip geliştirme ve tasarlamayı amaçlamaktadır. Sonuç olarak çocukların görsellerle, renklerle ve kavranabilir nesnelerle nasıl etkileşime girdiği ortaya konmuştur.

Antle ve diğerleri (2015), 5-8 yaş aralığında olan İngilizce ses, harf ilişkisinde zorluk yaşayan dislektik çocukları desteklemek için PhonoBlocks isminde kavranabilir bir sistem geliştirmişlerdir. PhonoBlocks, harflerin seslerini ayırt etmeyi sağlayan, ipucu olarak renkleri kullanan ve 3D kavranabilir harfler içeren bir sistemdir. Ayrıca sistem, dokunmatik ekranlı bir dizüstü bilgisayar, bir giriş platformu ve 27 kavranabilir harf içermektedir. Yazarlar (Fan ve diğerleri, 2016) PhonoBlocks için tasarım prensiplerini belirlemişlerdir. Fan ve diğerleri (2017), PhonoBlocks'un 7-8 yaşındaki özel öğrenme güçlüğü yaşayan (dislektik) çocukların bildikleri kelimeleri, bilmedikleri yeni kelimeleri ve her ikisini öğrenmelerinde etkili olduğunu bulmuşlardır. Yaptıkları durum çalışması bir ay sonra da öğrencilerin ögrenmeye devam ettiklerini göstermiştir. Bu sonuçlar, çocukların sistemle etkileşime girme biçimlerinin nitel analiziyle birleştiğinde, kavranabilir arayüzlerin temel tasarım özelliklerinin öğrenmeyi olumlu yönde etkilediğini de ortaya koymaktadır. Ayrıca, çocukların bireysel özelliklerinin öğrenme kazanımlarını ve tercihlerini etkilediğini de ortaya koymuşlardır.

Fan ve Antle (2015) İngilizce ses-harf ilişkisinde zorluk yaşayan 5-6 yaşındaki dislektik çocuklara yardım etmek için kavranabilir bir masaüstü sistemi geliştirmişlerdir. Sistem, öğrencilerin harflerin ses karşılıklarını öğrenmelerini sağlamak için dokuları ipucu olarak kullanmaktadır.

Pandey ve Srivastava (2011b) 8-12 yaş aralığında olan dislektik öğrencilere sıralı yönergeleri izlemelerini ve bunları hatırlamalarını kolaylaştıran Tiblo adında ses ve renk ipuçları içeren kavranabilir bir kullanıcı arayüzü geliştirmişlerdir. Sonuç olarak öğrenciler Tiblo'nun kullanımını ilginç bulmuşlar ve beğenmişlerdir.

Görüldüğü gibi, sınırlı sayıda olan bu araştırmalar, farklı teknolojilerle kavranabilir ara yüzler geliştirerek dislektik öğrencilerin okuma becerilerini arttırmayı hedeflemektedir. Bu çalışmanın amacı, özel öğrenme güçlüğü yaşayan ilköğretim 6-8. Sınıf öğrencileri için geliştirilen elle kavranabilir etkileşimli nesnelerle çalışan eğitsel mobil uygulamanın (çalışmanın bundan sonraki kısımlarında kavranabilir mobil uygulama adıyla anılacaktır) öğretmen kullanım durumunun incelenmesidir. $\mathrm{Bu}$ amaç doğrultusunda, öğretmenlerin bu uygulamayı kullanım durumlarını incelemek için öğretmene öncesinde herhangi bir eğitim verilmeksizin- kavranabilir mobil uygulama verilerek bunu öğrenciye uygulaması istenmiştir.

Araştırmacılar tarafindan geliştirilen uygulamada etkileşim, gerçek nesnelere oldukça benzer biçimde tasarlanan 3 boyutlu fiziksel nesnelere dokunma ve bu nesneleri tablete dokundurma ile gerçekleşmektedir. Nesneler Şekil 1'de sunulmuştur. Bu sistemin çalışma mantığı ise Şekil 2'de açıklanmıştır. 

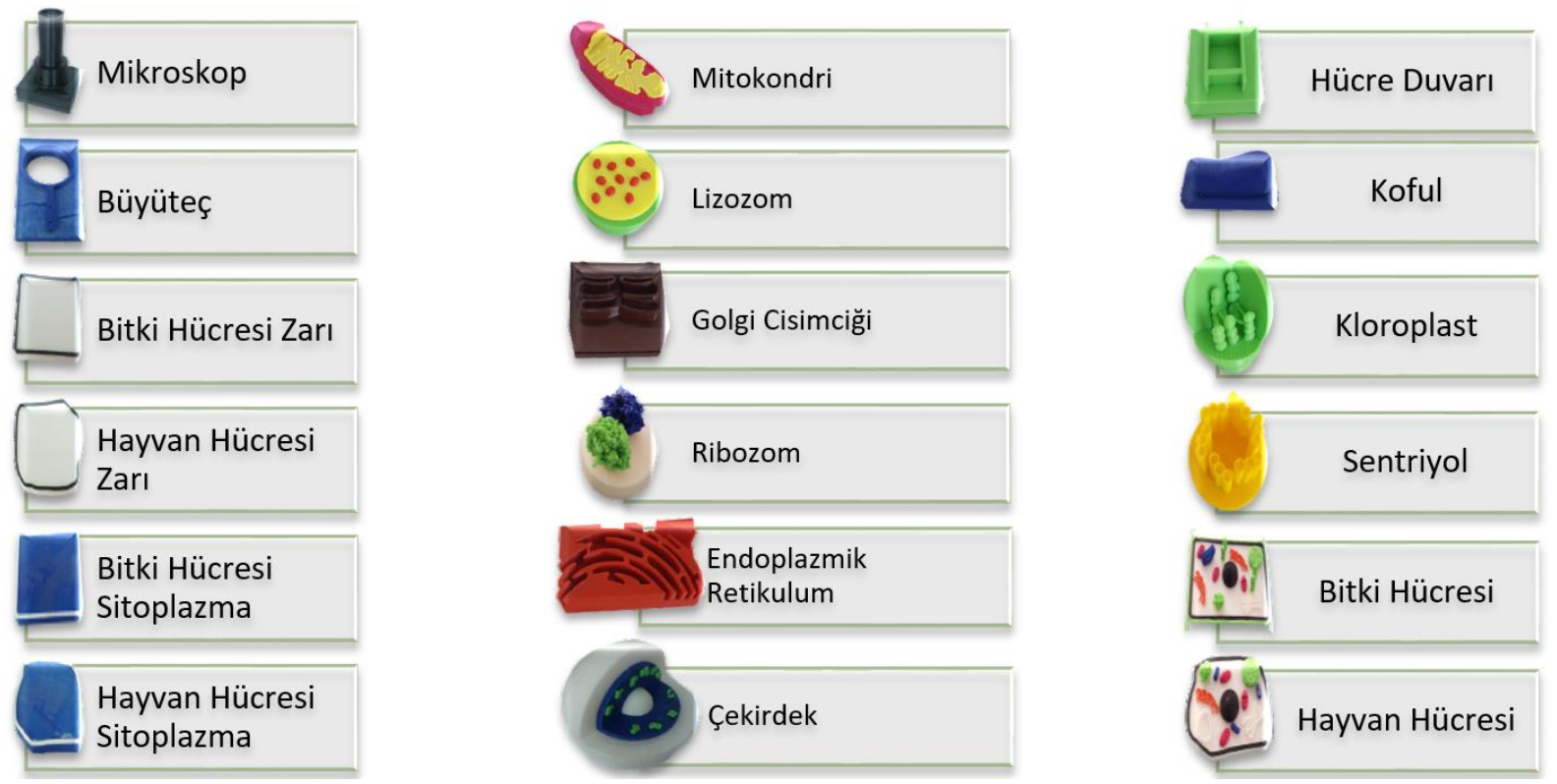

Şekil 1. 3 Boyutlu Fiziksel Nesneler

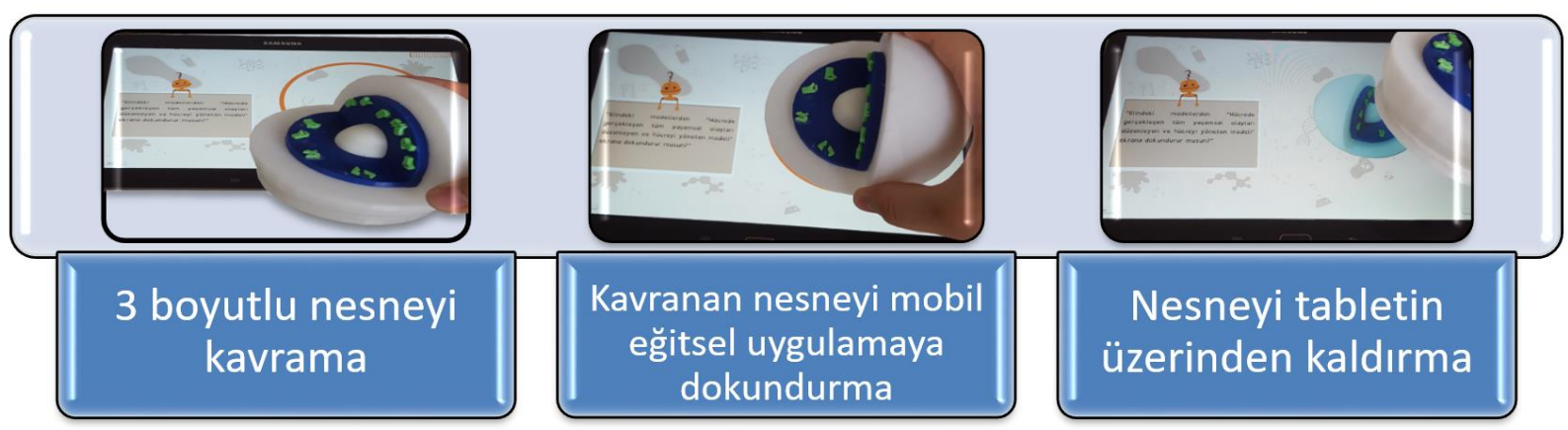

Şekil 2. Elle Kavranabilir Etkileşimli Nesnelerle Çalışan Eğitsel Mobil Uygulamanın Çalışma Prensibi

\section{Yöntem}

Çalışmada nitel araştırma desenlerinden araştırmanın doğasına uygun olan durum çalışması kullanılmıştır. Araştırma kapsamında, öğretmen kullanımını incelemek için öğretmene -öncesinde herhangi bir eğitim verilmeksizin- kavranabilir mobil uygulama verilerek bir öğrenciye uygulaması istenmiştir. Asıl uygulama öncesi pilot bir uygulama gerçekleştirilmiştir. Pilot uygulama ve asıl uygulama bir özel eğitim öğretmeni ve özel öğrenme güçlüğü yaşayan bir 6. Sinıf öğrencisi ile yürütülmüştür. Öğretmen uygulamalarının video kamera kaydı alınmıştır. Analizleri gerçekleştirmek için özel eğitim öğretmenleriyle görüşme yapılmıştır. Araştırmada veri toplama aracı olarak yarı yapılandırılmış görüşme formu kullanılmıştır.

\section{Katılımcilar}

Araştırmada, amaçlı örnekleme yöntemi kullanılmıştır. Patton (1990)'a göre amaçlı örneklem derinlemesine ve detaylı olarak yürütülen araştırmalarda zengin bilgiler içeren durumların incelenmesine yardımcı olur. Amaçlı örneklemede temel nokta, seçilen örneklemden genelleme yoluyla popülasyona ulaşmayı amaçlamak yerine önemli durumları veya olayları anlayıp ortaya koymaktır (Patton, 1999). İki özel eğitim öğretmeni $(n=2)$ ve iki ÖÖG yaşayan $(n=2)$ öğrenci çalışmanın katılımcılarını oluşturmaktadır (Tablo 1, Tablo 2). Özel eğitim öğretmenleri ile bire bir görüşmeler yapılmıştır. Katılımcılar seçilirken öğretmenlerin temel bilgisayar okuryazarı olmaları; öğrencilerin ise özel öğrenme güçlüğü yaşayan 6.-8. Sınıf öğrencileri olması ölçüt olarak belirlenmiştir. Katılımcıların ve özel eğitim merkezinin isimleri kodlanmıştır. 
Tablo 1.

Özel Eğitim Öğretmenleri ile İlgili Bilgiler

\begin{tabular}{lllll}
\hline Kod & Cinsiyet & Yaş & Deneyim & Özel Eğitim Merkezi \\
\hline P1 & Kadın & 26 & 2 Y1l & YCD \\
SET1 & Erkek & 29 & 8 Y1l & YI \\
\hline
\end{tabular}

Tablo 2.

Öğrencilerle İlgili Bilgiler

\begin{tabular}{llllllll}
\hline Kod & Cinsiyet & Yaş & Sınıf & Engel Türü & $\begin{array}{l}\text { Engel } \\
\text { Yüzdesi }\end{array}$ & $\begin{array}{l}\text { Özel Eğitim } \\
\text { Merkezi }\end{array}$ & $\begin{array}{l}\text { Okul } \\
\text { Türü }\end{array}$ \\
\hline FV & Kız & 11 & 6 & ÖÖG & N/A & YI & Devlet \\
MYP & Erkek & 11 & 6 & ÖÖG & 25 & YCD & Devlet \\
\hline
\end{tabular}

\section{Veri toplama araçları}

Yarı yapılandırılmış görüşme formu. Uygulamanın öğrencilerle birlikte kullanımından sonra özel eğitim öğretmenlerinin uygulama hakkındaki deneyim ve görüşlerini almak için yarı yapılandırılmış görüşme formu kullanılmıştır. Yarı yapılandırılmış görüşme formu sekiz sorudan oluşmaktadır. Sorular, uygulamayı kullanmaya başlama süreci $(n=2)$, uygulamayı kullanma süreci $(n=3)$ ve uygulamanın gelecekteki kullanımı $(\mathrm{n}=3)$ üzerine odaklanmıştır. Yarı yapılandırılmış görüşme formu, çalışmanın amacı ve kavranabilir mobil uygulamanın özellikleri dikkate alınarak araştırmacılar tarafından hazırlanmıştır. Sorular hazırlanırken ilgili literatürden yararlanılmıştır. Sorular hazırlandıktan sonra iki alan uzmanından görüş alınmıştır. Alan uzmanlarının görüşleri doğrultusunda gerekli düzeltmeler yapılmıştır. Alan uzmanlarının her ikisi de eğitim teknolojisi alanından olup deneyim süreleri 20 ve 8 yıldır. Soruların pilot uygulaması bir özel eğitim öğretmeni ile yapılmıştır. Herhangi bir değişikliğe ihtiyaç duyulmamıştır.

Gözlem formu. Uygulama sırasında alınan video kayıtları incelenirken gözlem formu kullanılmıştır. Form; karşılaşılan zorluklar, zayıf ve güçlü yönler, uygulamanın olumlu/ olumsuz yönler ve öğrenci tepkilerini içermektedir. Gözlem formu da çalışmanın amacı ve kavranabilir mobil uygulamanın özellikleri dikkate alınarak araştırmacılar tarafından hazırlanmıştır.

\section{Verilerin toplanması ve analizi}

Katılımcılar ve öğrenci velileri çalışmanın amacı ve gönüllük ilkesi konusunda bilgilendirilmiştir. Ailelerden izin formu alınmıştır. Video kamera, izin alınarak uygulama yapılan özel eğitim sınıfının bir noktasına, dikkati dağıtmayacak şekilde yerleştirilmiştir. Pilot ve asıl uygulamadan önce öğretmenlere herhangi bir eğitim veya yönerge içeren bir doküman verilmemiştir. Araştırmacılar, tableti ve kavranabilir nesneleri öğretmene vermiştir. Araştırmacılar öğretmenlere yalnızca öğrencinin nesneyi kavramas1 ve ardından nesneleri tablete dokundurması gerektiğini belirtmiştir. Her bir uygulamadan sonra, yarı yapılandırılmış görüşmeler gerçekleştirilmiştir. Görüşmeler katılımcılardan izin alınarak ses kayıt cihazıyla kaydedilmiştir. Pilot uygulama yaklaşı olarak 40 dakika; asıl uygulama yaklaşı 30 dakika sürmüştür. Pilot uygulama sonucunda asıl uygulama için herhangi bir değişiklik veya düzenleme yapılmamıştır. Verilerin analizinde betimsel analiz yöntemi kullanılmıştır. Betimsel analiz ile önceden araştırmacılar tarafından belirlenen üç kategoriye göre veriler özetlenmiş ve yorumlanmıştır. Öğretmenlerin görüşlerinden çarpıcı olanlarda doğrudan alıntıya başvurulmuştur (Yıldırım ve Şimşek, 2013).

\section{Bulgular}

Video kayıtları ve görüşmeler yoluyla toplanan veriler: 1) Uygulamayı kullanmaya başlama süreci, 2) Uygulamayı kullanma süreci ve 3) Uygulamanın gelecekteki kullanımı olmak üzere üç kategoriye göre analiz edilmiştir. 


\section{Uygulamayı kullanmaya başlama süreci}

İki özel eğitim öğretmeninin de (SET1 ve P1) ilk izlenim ve görüşlerinin çok olumlu olduğu görülmektedir. Ayrıca araştırmacılar, katılımcıların uygulamanın ilerleyen safhaları hakkında meraklı olduklarını fark etmiştir. SET1'in sözleri bu merak ve heyecanı ortaya koymaktadır:

Şekiller çok dikkatimi çekti. Güzel olmuş. Yani bu şekillerle [kavranabilir nesnelerle] daha kalıcı olabilir çocukların aklında. İlkten [sistemin nasıl çalıştığını] anlamaya çalıştım, ondan sonra hani çözünce şekilleri, hangisinin ne amaçla yapıldı ̆̆ını, çok faydalı olacă̆ını düşündüm. Özellikle, bitki hücresi ve hayvan hücresine hepsini yerleştirmişsiniz. O çok güzelmiş. (SET1).

Kullanıma başlama süreci katılımcılar tarafından tatmin edici bulunmuştur. Bunu destekler biçimde, P1 bu süreç hakkında görüşlerini şu şekilde ortaya koymaktadır:

İlk gördüğ̈̈mde konu aslında benim de çok sevmediğim konulardan birisiydi öğrenciyken. Yani şey materyalleri canl görmek ve onlara dokunuyor olmak aslında "gördüğümüz A4'tekinden..." çok daha iyi geldi yani "Evet bu artık üç boyutlu ve bunun ne olduğunu inceleyebilirimi yarattı̆̆ için çok hoşuma gitti. (P1)

Öğretmenlerin ortaya koyduğu yansımalar birbirlerini desteklemektedir ve öğretmenlerin diğer safhalarda da olumlu ilk izlenimleri devam etmektedir. Öğrencilerin ilk tepkilerinin de olumlu ve meraklı olduğu görülmektedir. P1, öğrencisinin (MYP) deneyimlerini şu şekilde ifade etmektedir: "MYP zaten şey yaptı direk kutularda bunlar ne ki?" diye kurcalamaya başladı. "Birazdan öğreneceğiz." dediğim zaman "ne zaman öğreneceğiz?" işte "Bunların hepsini mi kullanacağız?" gibi çok merakla onların ne olduğunu keşfetmeye aslında yöneldi." (P1).

P1'in sözlerinden, uygulamanın ÖÖG yaşayan öğrencilerin ve öğretmenlerinin dikkatini çektiği anlaşılmaktadır. Görüşmelerde ortaya çıkan bu yorumlar gözlemlerde de doğrulanmıştır. Araştırmacılar, uygulamanın başında nesnelerin MYP'nin dikkatini çektiğini gözlemlemiştir. MYP'nin bazı nesneleri daha önceden bildiği için mutlu olduğu gözlenmektedir. Bununla birlikte, aynı zamanda yeni nesneler hakkında bilgi edinmek için oldukça meraklı olduğu görülmüştür.

Ayrıca, tüm katılımcılar kavranabilir mobil uygulamanın kullanımını kolay olarak algılamaktadır. Bu durumun altını P1 şu sözlerle çizmektedir: "Ya aslında çok zor değildi zaten tarif ediyordu birçoğunu ilk başlangıçta." (P1).

Benzer biçimde, SET1 şunları ifade etmektedir: "Çocuklar gibi ben de ilk başta inceledim. Nasıl yapıyoruz, nasıl dokunduruyoruz filan. Sonra tabletten aldığımız tepkilere göre öğrenmeye başladım. Tutuş şekli de önemliymiş. Onu da fark ettik sonradan.” (SET1).

Katılımcılar uygulamanın kullanımını öğrencilerin de kolay olarak algıladığını belirtmektedir. SET1 öğrencisinin kavranabilir mobil uygulamanın nasıl kullanılacağını kolaylıkla öğrenebildiğini ifade etmektedir:

Öğrencim başta yapamayacă̆ını düşündü. Sonra tekrar deneme yoluna gitti. Hani biraz da yardımım olmuş olabilir, bir iki bir şey gösterdim. Ama ondan sonra kavradı pratik. Kendi zaten olmayınca çevirmeye başladı düz koydu, olmadı ters çevirdi koydu. Deneme yanılma yoluyla ögrendi. (SET1)

Öğretmenlerin öğrencileri hakkındaki görüşleri ve uygulamanın ilk aşamadaki kullanımı hakkındaki tüm deneyimleri, uygulamanın kolay kullanılabildiğine işaret etmektedir. P1, öğrencisi MYP ile ilgili gözlemlediği durumu şu şekilde paylaşmaktadır: “...Zorlandı mı? Hayır, çok zorlanmadı. Çünkü tek yapması gereken yanındaki kutudan o materyali çekip oraya okutmaktı... O'nun için ama keyifli ve eğlenceliydi diye düşünüyorum.” (P1).

Ayrıca P1 uygulamanın öğrencide merak uyandırdığını da eklemektedir:

MYP zaten böyle mekanik elektronik vs. ne varsa hepsine çok merakl bir çocuk. Ben hatta bir ara şey dedim herhalde, "MYP birazdan bunun altını açıp içine bakacaktır." dedim çünkü şey yaptı. Aldı altına baktı "bu şimdi buradan mı hissediyor. Koyuyoruz ama hepsinde siyah bir şey varsa nasıl anllyor?" vs. MYP'nin çok dikkatini çekti çünkü onun çok ilgisini çeken bir alan 
zaten bu. Hele ki 3 boyutlu olunca ki, MYP bir de özel öğrenme güçlüğ̈̈ ögrencilerinden birisi. Bir A4 onlara yetmiyor. Öyle görmek evet gerçekten onun için çok dikkat çekiciydi... (P1)

Uygulamanın ilk aşamadaki kullanımında olumlu deneyimlerin yanı sıra yaşanan güçlükler de olmuştur. MYP genel olarak her nesneyi hafifçe ekranın üzerine bırakıp kaldırmadığı için bazen dönüt gelmemiş ancak birkaç denemeden sonra gelmiştir. Ayrıca, parmağını da ekrana dokundurmuştur. P1 görüşme esnasında bu durumu birkaç kez vurgulamıştır. P1 kullanma sürecinde bazen bu dokundurma problemlerini yaşadıklarını belirtmiştir:

Sadece bir ara hani orada okuturken, "Ya okumadı." deyip işte tablete bastırmaya falan çalıştı. "MYP bir çekip bir daha mı koysak bastırmanın bir yararı olmayacak çünkü." falan diye konuştuk...[kavranabilir mobil uygulamayı kullanmak] Öyle O'nun için ama keyifli ve eğlenceliydi diye düşünüyorum. (P1)

SET1 ekranda verilen dokundurma çemberiyle ilgili olarak yaşadıkları sorunu dile getirmiştir. Ekranda, uygulama boyunca öğrencilerin kavradıkları nesneleri dokundurmaları için bir dokundurma çemberi mevcuttur. SET1, dokundurma alanının çember şeklinde olmasının kendisini ve öğrencisini yanlış yönlendirdiğini belirtmiştir. SET1 ve öğrencisi sadece yuvarlak olan nesneleri dokundurmaları gerektiğini düşünmüşlerdir: “...Hani ben çemberi görünce zannettim ki sadece altı yuvarlak olanlara dokunduracağız diye düşündüm.” (SET1).

Gözlem sırasında, ilk başta, tablet ekranında sadece daire olanlara dokundurdukları, dikdörtgen veya kare olanları dokundurmadıkları; kullanıma başlama sürecinde, uygulamanın nasıl kullanılacağını keşfetmek için kısa bir süre harcamış oldukları görülmüştür.

SET1 ve P1 uygulamanın en başında sunulan, ögrenciye hem uygulama hem nesnelerin nasıl kullanılacağı konusunda aşinalık sağlayan alıştırma ekranını beğendiklerini dile getirmişlerdir. P1 alıştırma ekranının kullanımı kolaylaştırdığını vurgulamıştır: "Zaten yazılımda şey de [alıştırma ekranı] ile başlıyor. Parçaları tanıtmak üzerine gittiği için o zaten senin için kolaylaştırıcı. Hatta biz hani MYP tamam anladım ben dedi ve biz onu geçtik. Hani bütün parçaları [kavranabilir nesneleri] tanıtmadık." (P1).

\section{Uygulamayı kullanma süreci}

Hem SET1 hem de P1 uygulamayı kullanma sürecini çoğunlukla kolay olarak nitelendirmiştir. Tüm katılımcıların, uygulamayı kullanırken zevk aldıkları gözlemlenmiştir. Buna ek olarak, uygulamayı kolaylıkla kullandıkları ve bu uygulamayı kullanmaktan memnun oldukları da görülmüştür.

Uygulamanın konu anlatımı kısmında öğrencinin hangi nesneyi ekrana dokundurması gerektiğine dair ekranın sol üst köşesinde nesnenin görseli yer almaktadır. Öğretmenler sözü edilen görsellerin uygulamanın kullanımını kolaylaştırdığını dile getirmiştir. Ancak P1 kendisinin ve ögrencisinin ilk etapta bu görseli fark edemediklerini ve uygulamanın en başta bu özelliği tanıtması gerektiğini eklemiştir. P1 bu durumu şu sözlerle ifade etmektedir:

[İlk başta] bir şeyi çözmemiz "Aa evet şurada zaten görselin resmi varmış buna baksaymışız ya keşke." dediğimiz bir süreç oldu. İlk bir onu fark ederken bir şey yaptı. Belki orada hani ya da söyledi de biz MYP ile o an duymamış olabiliriz. "Size zaten resmini göstereceğiz bakın." gibi bir ibare belki vardır ama biz duyamadık MYP ile... [Yoksa] o zaman olursa çok iyi olur. (P1)

SET1 öğrencisinin uygulamayı kolaylıkla kullandığını belirtmiştir. SET1 tablet uygulamasının oldukça açılayıcı olduğunu ifade etmiştir. SET1 uygulamanın öğretmenleri derse daha hazırlıklı kılacağını da eklemiştir.

Mobil uygulamay1 kullanırken hem MYP hem P1'in yeni bilgileri görmekten ve keşfetmekten memnun olduğu gözlemlenmiştir. Buna paralel olarak, P1 ve SET1 kavranabilir mobil uygulamay1 kullanmanın kalıcı öğrenmeyi sağlayabileceğini belirtmiş̧ir. Bu durumu SET1 şu şekilde açıklamaktadır: "Çocuk yaparak, yaşayarak öğreniyor. Bu da bizim sistemimizde önemli bir şey, [öğrenme] daha kalıcı [oluyor]. Bilgilerin yani yaklaşı \%70'i yaparak, yaşayarak kalıcı oluyor." (SET1). 
SET1 uygulamanın sağladığı etkileşimin çocuğun öğrenmesini kolaylaştıracağını ifade etmiştir: "Öğrenci kendini derste daha aktif olarak şey yaptığı için, kendi basıyor, çekiyor. O yüzden öğrenmesi daha kolay oluyor." (SET1).

Ayrıca şunları eklemiştir: "Yönlendirmeleri falan iyiydi tabletin. Çocuk da zaten yanlış yaptığında hani şey yapmadı, en azından morali bozulmadı. Yönlendiriyor ne de olsa, bir şekil yeniden denedi, hani sürekli denedikçe de öğrendi diye düşünüyorum.” (SET1).

Benzer şekilde, P1 de etkileşimin uygun düzeyde olduğunu belirtmektedir. Öğrencinin uygulamanın verdiği yönergeleri anladığını ve bunlara tepki verdiğini de ifade etmektedir. Bununla birlikte, P1 şunları eklemektedir:

Çok mikro boyutlar değildi o çok güzeldi. Yani çocuklar zaten bunları çok ufak görüyorken, büyük görmek onu çok daha hoşuna gitti. Bu açıdan çok iyiydi. Çünkü inceleyebileceği bir şey. Onun dışında çok bence etkileşim güzel gidiyor, yani sınırlanmiyor ve onun ilgisini çekebilecek düzeyde olduğunu düşünüyorum. (P1)

P1 uygulamanın sağladığı soru yanıt etkileşimini şu sözlerle açıklamaktadır: "Ne olduğunu anlatıp birde bunu kontrol sorusu olarak da sorması güzel, ya evet bu söylediğim şeyi anladın mı diye soruyordu çünkü...” (P1).

P1, öğrencilerin dokunduracağı nesnelerin dokundurma çemberinin içinde şeffaf görüntülerinin yer almasının etkileşimi artıracağının altını çizmiştir. Ayrıca, şeffaf görüntülerin sunulmasının öğrencilerin tüm bu adımları etkili bir şekilde tamamlamasına yardımcı olduğunu vurgulamıştır.

Gözlemler sırasında, MYP'nin alıştırma sorularını doğru yaptıkça mutlu olduğu görülmüştür. P1 uygulamanın öğrenciyi motive ettiğini ve uygulamanın sonuna kadar öğrencinin merakını sürdürmesine yardımcı olduğunu belirtmiştir:

En sonunda gene bir anlatım bittikten sonra mini bir test [venn şeması] vardl. Orda da tekrar "Doğru mu? Değil mi?" diye tekrar bakmış oluyordu. "Yani bütün bunlarl yapabildik mi? Oldu mu?" vs. Hani MYP normalde" Yaptım işte" deyip geçen bir çocuk. "Yani tamam, bitti. Artık önemli değil, oldu mu ama şimdi" diye sorması bile benim için artı bir şey çünkü onun olup olmadiğın bile merak ediyor ve bu onun bana göre "Evet bunu öğrenmeye çalışıyorum." deme şekli. (P1)

P1 uygulamanın renk yönünden avantajını şu şekilde ifade etmektedir:

Ya ben renklerin canlı olmasının çocuklarda çok işe yaradiğını düşünüyorum ve tablet uygulamasinda renklerin hepsi canliyd. Bunun yanı sira materyaller zaten hemen hemen bütün fen bilgisi kitaplarında o anlatılan renklerde tasarlanmıştı yani. Sitoplazmayı tutup bir turuncu göstermiyor yine bize o materyallerde nasıl anlatıllyorsa yine o renk. Mümkün olduğunca ona çok yakın renkler seçilmiş. (P1)

SET1 ve P1'in öğrencilere kullanım esnasında profesyonel şekilde rehberlik ettikleri gözlemlenmiştir. Öğrencileri bir hata yaptığında doğru cevabı açıkça söylemeksizin öğrencilere yönlendirme yapmışlardır. P1 uygulamanın öğretmen rehberliğini engellemediğini belirtmiştir.

Öğrencilerin baştaki konu anlatımı kısmında ve uzun yönergelerin bazılarında sıkıldıkları gözlemlenmiştir. Benzer şekilde, son test kısmında da aynı durum görülmüştür.

SET1 öğrencinin nesneleri bazen dikkatsizce kullandığını vurgulamıştır. Daha özel olmak gerekirse, nesneleri rasgele tablet ekranına dokundurmuştur. Gözlem bulguları bunu onaylamaktadır. Örneğin, büyüteç, mikroskop, hayvan hücresi ve bitki hücresi modelleri, venn şeması alıştırmasında dokundurulmamalıdır. Dokundurulmaması gerektiği halde öğrenci bu nesneleri dokundurmuştur. Dolayısıyla, yanlış nesneler dokundurulduğu için uygulama düzgün çalışmamıştır. Bunun nedeninin ilk oturum olmasından kaynaklandığı düşünülmektedir.

SET1, öğrencisinin bazı dokundurma sorunları yaşadığını belirtmiştir. Gözlemlere göre, öğrenci nesne tabletle etkileşim halindeyken, nesneyi tablet üzerinde döndürmüştür.

Daha önceden bahsedildiği gibi, MYP (öğrenci) genel olarak her nesneyi hafifçe ekranın üzerine bırakıp kaldırmadığı için bazen dönüt gelmemiş ancak birkaç denemeden sonra gelmiştir. Ayrıca, MYP 
parmağını da ekrana dokundurmuştur. P1 öğretmen görüşme esnasında bu durumu birkaç kez vurgulamıştır. P1 kullanma sürecinde bazen bu dokundurma problemlerini yaşadıklarını belirtmiştir. P1 kullanıcı kılavuzunun kullanımı kolaylaştıracağını belirtmiştir:

Bir tek ufak tefek şeyler o da materyalleri nasıl kullanacağımızı dair eğitimin olmamasından kaynaklıymış. Bu çok basit o ögretmene rehberlik, yani öğretmene rehberlik edip onu nasıl kullanacağı anlatıldığında sadece çok hızla aşılacak bir şey... Bunlar çok ufak ve sinırlılığı çok kolay aşılacak şeyler diye düşünüyorum. (P1)

Öğretmenlerle yapılan görüşmelerden uygulamanın kullanımının kolay olduğu gibi kavramların daha etkili bir şekilde öğrenilmesi için de fırsatlar sağladığı çıkarımı yapılabilir. Gözlemlerde, ögretmenlerin önceden eğitim almadan uygulamayı kullanma konusunda yetkin ve rahat oldukları görülmüştür. Uygulamaya alışkın olmamaları nedeniyle zorluk yaşadıkları zamanlar olmasına rağmen, birkaç deneme sonrasında bu sorunları aşabilmişlerdir.

\section{Gelecekteki Kullanım}

Görüşme ve gözlem sonuçları hem SET1 hem de P1'in uygulamayı sınıflarında kullanmak için istekli olduklarını göstermektedir.

SET1 öğretmen kavranabilir mobil uygulamanın fen dersinin başka konularında veya matematik, geometri, dil gibi başka derslerde kullanmak istediğini belirtmiştir. Ayrıca kavranabilir mobil uygulamanın yaparak öğrenme, kalıcı öğrenme ve görsel öğrenmeyi sağlayacağını belirtmiştir. Benzer biçimde, P1 şu şekilde açıklamaktadır:

Fen bilgisi [dersinin] bence hemen hemen hepsinde kullanilabilir. Ben bunu sosyal bilgilere de gayet uyarlayabilirim. Tutup bir Türkiye haritasında 7 bölgeleri de çocuğa verip hadi birleştir de yapıp o bölgeyi tanttırken o bölgenin üzerine ağaç da diktirtebilirim. Ya da oranın bitki örtüsünü serdirtebilirim. ...Onun dışında matematik de dâhil olmak üzere bir şekilde kullandırtabilinir... (P1)

Her iki öğretmen de öğretim etkinliğini arttırmada, öğrenmeyi sağlamada ve öğrenciyi motive etmede uygulamanın önemli bir araç olduğunu vurgulamıştır. $\mathrm{Bu}$ nedenle, öğretmen görüşleri uygulamanın gelecekte uygulanabileceğini gözler önüne sermektedir. Ayrıca, öğretim materyallerinin standart ve tekdüze öğretim yaklaşımlarına dayalı olarak geliştirilmemesi gerektiğini de vurgulamışlardır.

P1 ek olarak diğer öğretmenlere de uygulamayı kullanmayı önermiştir:

Yani düşünürüm çünkü hep söylediğim gibi yani artık teknoloji çağındayız ve bir A4 [eğitsel bir materyal olarak] yeterli değil. Yani izlediğimiz bir video bile bazen tek düze olduğu zaman yetmiyor, çocukları karşılamıyor artık. Çünkü çok fazla uyarana maruz kalmaya çok alıştık... Yani materyalleri görselleştirmek ve ona dokunabilmek, her ögretmenin aslında kullanması gereken bir şey diye düşünüyorum. Yani bitti ya A4 çağı bitti bence bunu ögretmenlerin artık fark etmesi gerekiyor... Ögretmek daha kolay oluyor. Çünkü zaten çocuğa materyali veriyorsun ve bak, incele diyebiliyorsun yani... (P1)

Özetlemek gerekirse, özel eğitim öğretmenleri, kavranabilir uygulamaların kendilerine sınıfta daha iyi eğitim verme şansı sağlayacağına inandıklarını raporlamışlardır.

\section{Tartışma}

Araştırmanın bulguları, öğretmenlerin ve ÖÖG yaşayan öğrencilerin kavranabilir mobil uygulamayla ilgili ilk tepkileri ve izlenimlerinin olumlu olduğunu göstermektedir. Katılımcıların uygulamanın ilerleyen aşamaları hakkında meraklı oldukları gözlemlenmiştir. Bunun yanı sıra, uygulamayı kullanıma başlama süreci onlar için tatmin edicidir. Benzer biçimde, Haro, Santana ve Magaña (2012), down sendromlu öğrencilerin kavranabilir bir arayüzü kullanırken meraklı ve ilgili olduklarını bulmuşlardır. Buna ek olarak Haro ve diğerleri (2012), öğretmenlerin izlenimlerinin çok olumlu olduğunu ve kavranabilir sistemi kullanmaya ilgi duyduklarını belirtmişlerdir. Başka bir çalışmada, Bodén, Dekker 
ve Viller (2011), çocukların başlangıçta kavranabilir sistemi keşfetmeye ve öğrenmeye meraklı ve ilgili olduklarını ifade etmektedirler. Aynı şekilde, görüşme sonuçları öğretmenlerin kavranabilir mobil uygulamayı kullanma konusunda istekli olduklarını göstermektedir. Buna paralel olarak, JadanGuerrero, Jaen, Carpio ve Guerrero (2015), öğretmenlerin kavranabilir sistemi ilginç ve keyifli bulduklarını vurgulamışlardır. Pandey ve Srivastava (2011b), ÖÖG yaşayan çocukların nesneler kendilerine sunulur sunulmaz bunlarla ilgilendiğini ortaya koymuşlardır. Buna ek olarak, çocukların kavranabilir mobil uygulamayı kullanmak için heyecanlı ve meraklı oldukları görülmüştür. Marco, Cerezo, Baldassarri, Mazzone ve Read (2009) de, öğrencilerin ilk izleniminin merak dolu ve eğlenceli olduğunu vurgulamaktadırlar. Hatta öğrencilerin kavranabilir sistemi daha fazla kullanmak istediklerini belirtmişlerdir.

Sonuçlar, öğretmenlerin ve ÖÖG yaşayan öğrencilerin kavranabilir mobil uygulamanın kullanımını kolay olarak algıladıklarını göstermektedir. Benzer sonucu Fan ve diğerleri (2017) de ortaya koymuştur. Ancak, sadece ilk başta çok az güçlük yaşamışlardır. Bunun nedeninin, öğretmenlerin deneyimsizliği ve sisteme olan yabancılıkları olduğu söylenebilir. Yine de araştırmacılar, gelecekteki çalışmalar için bu durumu geliştirilmesi gereken nokta olarak ele almışlardır. Bu yoruma destek olarak, Jadan-Guerrero ve diğerleri (2015), öğretmenlerin kavranabilir sistemi öğrencilere kullandırmadan önce kendilerinin denemesinin önemli olduğunu, bu sayede öğrencilerinin kullanımına daha iyi bir şekilde yardım edebileceklerini belirtmişlerdir. Buna karşılık, Haro ve diğerleri (2012) kavranabilir sistem kullanımının bu öğrenciler için fare kullanmaktan daha kolay olduğunu vurgulamışlardır. Önemli bir kullanılabilirlik sorunu olmasa da, ÖÖG yaşayan öğrencilerin dokundurma ile ilgili sorun yaşadıkları gözlemlenmiştir. Bunun nedeninin ilk oturum olmasından kaynaklandığı düşünülmektedir. Ayrıca öğretmenlerin, öğrencilere nesneleri döndürmemeleri, nesneyi dokundurduktan sonra tablet üzerinden çekmeleri konusunda rehberlik etmeleri gerekmektedir. Bu sorunun üstesinden gelmek için, görüntü veya video içeren küçük bir tanıtım metni hazırlanabilir. Böylece, öğretmenler bu küçük noktaları öğrenebilir ve öğrencilerini doğru bir şekilde yönlendirebilirler. Benzer şekilde, Marco ve diğerleri (2009), öğrencilerin kavranabilir oyuncakları küçük bir alıştırma ile kullanabileceğini ortaya koymuşlardır. Bunlara paralel olarak, Bodén ve diğerleri (2011), başlangıçta öğrencilerin kavranabilir nesneleri yanlış yerleştirdiklerini ancak daha sonra çabucak öğrendiklerini belirtmişlerdir.

Ayrıca mevcut çalışma, tüm katılımcıların uygulamayı kullanırken eğlendiğini ortaya koymaktadır. Gözlem sonuçları da bu durumu desteklemektedir. Yalnızca öğrencilerden birinin uzun yönergelerde ve test kısımlarında bir miktar sıkıldığı gözlenmiş̧tir. Öğrenci yorulduğu için bu durum gözlenmiş olabilir. Jadan-Guerrero ve diğerleri (2015) kavranabilir sistemi kullanan çocukların keyifli vakit geçirdiklerini belirtmişlerdir. Bir başka çalışmada, Falcão ve Price (2009), özel eğitim alanında çalışan öğretmenlerin kavranabilir nesneleri kullanma konusunda çok hevesli olduklarını belirtmişlerdir. Bouck, Bassette, Taber-Doughty, Flanagan ve Szwed (2009), hafif engelli öğrencilerin kavranabilir aracı kullanmaktan keyif aldığını ortaya koymuşlardır. Sitdhisanguan, Chotikakamthorn, Dechaboon ve Out (2012) ise kavranabilir sistemi kullanan öğrencilerin çok hevesli olduklarını ve uygulamayı kullanmaktan zevk aldıklarını belirtmişlerdir. Benzer şekilde, Starcic, Cotic ve Zajc'in (2013) çalışmasında öğretmenler, öğrencilerinin kavranabilir sistemi kullanırken eğlendiklerini gözlemlemişlerdir.

Araştırma sonuçları katılımcıların uygulamayı kullanırken istekli olduklarını göstermektedir. Kavranabilir mobil uygulama, ÖÖG yaşayan öğrencilerin zihinlerindeki farkındalığın artırılması için bir araç görevi görebilir. Daha yüksek seviyede motivasyona sahip olarak öğrenme sürecinde aktif bir katılımcı rolünde yer almak bu farkındalığın nedenlerinden biri olabilir. Bu sonuç, yalnızca bir öğretmen tarafından ifade edilse de, ÖÖG yaşayan öğrencilerin zihninde bu tür bir değişimi dolaylı yoldan gösteren ifade ve gözlemler mevcuttur. Bu açıdan bakıldığında uygulama, katılımcılar tarafindan yalnızca bir öğrenme aracı olarak değil, öğrencileri aktif öğrenme düşüncesine yönlendiren bir araç olarak yorumlanmaktadır. Jadán-Guerrero, Guerrero, López, Cáliz ve Bravo (2015) çalışmalarında kavranabilir uygulamayı kullanırken öğretmen ve öğrencilerin motivasyonunun arttığını belirtmektedirler. Yukarıda belirtilen niteliklere ek olarak, renklerin uygun biçimde kullanımı da öğrenmeyi ve algılamayı kolaylaştırabilir. Doğru renk kullanımı ciddi kazanımlar getirebilir. Ayrıca uygulama, kitaplardaki ve uygulamadaki görüntüler arasında bir köprü oluşturabilir. Jadán-Guerrero ve diğerleri (2015) da kavranabilir sistemin öğrencileri motive ettiğini, öğrencilerin öğrenme süreci için yararlı olduğunu ifade etmişlerdir. Bunlara paralel olarak, Cobb, Mallett, Pridmore ve Benford (2007), ögretmenler kavranabilir sistemi öğrenme için bir motivasyon kaynağı olduğunu kabul etmiş̧lerdir. 
Sonuçlar, tüm katılımcıların kavranabilir etkileşimi sevdiklerini ortaya koymaktadır. Öğretmenler, uygulamanın öğrencilerin öğrenmesini kolaylaştıracağını düşünmektedirler. JadanGuerrero ve diğerleri (2015) de öğretmenlerin kavranabilir etkileşimle motive olduklarını ortaya çıkarmışlardır. Buna ek olarak, öğretmenler kavranabilir etkileşimi öğrenciler için eğlenceli ve ilginç olarak tanımlamıştır. Benzer şekilde, Jadán-Guerrero ve diğerleri (2015) öğretmenlerin kavranabilir etkileşimin, dijital ve fiziksel etkileşimi birleştirdiği için tamamlayıcı olduğunu düşündüklerini vurgulamışlardır. Aynı şekilde, Haro ve diğerleri (2012), down sendromlu bir öğrencinin, etkileşim türünün yeni olması nedeniyle kavranabilir sistemi ilginç bulduğunu belirtmişlerdir. Hengeveld, Voort, Van Balkom, Hummels ve de Moor (2007), öğrencilerin kavranabilir materyaller ve sağladıkları etkileşim sayesinde okuma yazma becerilerini kolayca kavrayabileceklerini ortaya koymuşlardır.

Ayrıca, öğretmenler, kavranabilir mobil uygulamanın, çok-duyulu etkileşimi sağlaması nedeniyle öğrencilerin kalıcı olarak öğrenmelerine yardımcı olabileceğini belirtmişlerdir. Geleneksel yaklaşımların yerine, çok duyulu öğretim en etkili araçlarla işe koşulmalıdır. Bu nedenle, uygulama öğrenmeyi kolaylaştırabilir ve soyut kavramları somutlaştırır. Buna paralel olarak, Jadan-Guerrero ve diğerleri (2015) öğretmenlerin genel izlenimini kavranabilir sistemin öğrencilerin öğrenmesini kolaylaştırabileceği yönündedir. Bouck ve diğerleri (2009) öğretmenlerin ve öğrencilerin kavranabilir sistemin çarpma işlemini öğrenmede faydalı olduğunu düşündüklerini belirtmişlerdir. Bunlara benzer şekilde, Jadán-Guerrero ve diğerleri (2015), öğretmenlerin kavranabilir sistemin okuma yazma becerilerini geliştirmek için faydalı olduğunu düşündüklerini belirtmişlerdir.

Sonuç olarak, öğretmenler bu tür materyalleri gelecekte kullanmak istemişlerdir. Sınıflarında kavranabilir mobil uygulamaların kullanılması konusunda çok olumlu ve istekli olduklarını belirtmişlerdir. Uygulamanın öğretmen rehberliğini engellemediği ifade edilmiştir. Bununla birlikte, uygulamaya bireysel kullanım seçeneğinin eklenebileceğini ifade etmiştir. Bu şekilde öğrencilerin kendi kendine çalışabileceği olasılığı ortaya çıkmaktadır.

Buna ek olarak, kavranabilir mobil uygulamayı diğer konularda ve derslerde de kullanabilirler. Benzer şekilde, Haro ve diğerleri (2012), öğretmenlerin gelecekte kavranabilir sistemi kullanmak istediklerini ortaya koymuşlardır. Bu tür uygulamalar, özellikle soyut kavramları öğrenmeyi kolaylaştıracaktır.

Bu çalışma, özel öğrenme güçlüğü yaşayan ilköğretim 6-8. Sınıf öğrencileri için geliştirilen kavranabilir mobil uygulamanın öğretmen kullanım durumu konusunda aydınlatıcı bir bakış açısı sunmakla birlikte, gelecekteki çalışmalarda kullanılabilirlik araştırmaları yürütülebilir. Göz hareketlerini izleme cihazı kullanılarak kavranabilir mobil uygulamanın kullanışl1lığ konusunda farklı çalışmalar yapılabilir.

\section{Kaynaklar}

Antle, A. N. (2007). The CTI framework: informing the design of tangible systems for children. Proceedings of the First International Conference on Tangible and Embedded Interaction, USA, 195-202. doi: 10.1145/1226969.1227010

Antle, A. N., Fan, M. ve Cramer, E. S. (2015). PhonoBlocks: A tangible system for supporting dyslexic children learning to read. Proceedings of the Ninth International Conference on Tangible, Embedded, and Embodied Interaction, USA, 533-538. doi: 10.1145/2677199.2687897

Bodén, M., Dekker, A. ve Viller, S. (2011). Discovery table exploring the design of tangible and ubiquitous technology for learning in preparatory classrooms. Proceedings of the 23rd Australian Computer-Human Interaction Conference, Australia, 54-57. doi: 10.1145/2071536.2071543

Bouck, E. C., Bassette, L., Taber-Doughty, T., Flanagan, S. M. ve Szwed, K. (2009). Pentop computers as tools for teaching multiplication to students with mild intellectual disabilities. Education and Training in Developmental Disabilities, 44(3), 367-380.

Cobb, S., Mallett, A., Pridmore, T. ve Benford, S. (2007). Interactive flashlights in special needs education. Digital Creativity, 18(2), 69-78.

Eisenberg, M., Eisenberg, A., Hendrix, S., Blauvelt, G., Butter, D., Garcia, J., Lewis, R. ve Nielsen, T. (2003). As we may print: new directions in output devices and computational crafts for children. Proceedings of the 2003 Conference on Interaction Design and Children, UK, 31-39. doi: $10.1145 / 953536.953543$ 
Falcão, T. P. ve Price, S. (2009). The role of tangible technologies for promoting effective inclusion. Workshop on Creative Interactive Play for Disabled Children, Italy, (ss. 16-19).

Falcão, T. P. ve Price, S. (2010). Informing design for tangible interaction: a case for children with learning difficulties. Proceedings of the 9th International Conference on Interaction Design and Children, Spain, içinde (ss. 190-193). doi: 10.1145/1810543.1810568

Fan, M. ve Antle, A. N. (2015). Tactile letters: A tangible tabletop with texture cues supporting alphabetic learning for dyslexic children. Proceedings of the Ninth International Conference on Tangible, Embedded, and Embodied Interaction, USA, içinde (ss. 673-678). doi: $10.1145 / 2677199.2688806$

Fan, M., Antle, A. N. ve Cramer, E. S. (2016). Design rationale: Opportunities and recommendations for tangible reading systems for children. Proceedings of the The 15th International Conference on Interaction Design and Children, United Kingdom, içinde (ss. 101-112). doi: $10.1145 / 2930674.2930690$

Fan, M., Antle, A. N., Hoskyn, M., Neustaedter, C. ve Cramer, E. S. (2017). Why tangibility matters: A design case study of at-risk children learning to read and spell. Proceedings of the $2017 \mathrm{CHI}$ Conference on Human Factors in Computing Systems, USA, içinde (ss. 1805-1816). doi: $10.1145 / 3025453.3026048$

Fishkin, K. P. (2004). A taxonomy for and analysis of tangible interfaces. Personal and Ubiquitous Computing, 8(5), 347-358.

Florian, L. (2004). Uses of technology that support pupils with special educational needs. L. Florian ve J. Hegarty (Yay. haz.), ICT and special educational needs: A tool for inclusion, içinde (ss. 720). Maidenhead: Open University Press.

Haro, B. P. M., Santana, P. C. ve Magaña, M. A. (2012). Developing reading skills in children with Down syndrome through tangible interfaces. Proceedings of the 4th Mexican Conference on Human-Computer Interaction, Mexico, içinde (ss. 28-34). doi: 10.1145/2382176.2382183

Hengeveld, B., Voort, R., van Balkom, H., Hummels, C. ve De Moor, J. (2007). Designing for diversity: developing complex adaptive tangible products. Proceedings of the 1st International Conference on Tangible and Embedded Interaction, USA, içinde (ss. 155-158). doi: $10.1145 / 1226969.1227002$

Horn, M. S., Solovey, E. T., Crouser, R. J. ve Jacob, R. J. (2009). Comparing the use of tangible and graphical programming languages for informal science education. Proceedings of the SIGCHI Conference on Human Factors in Computing Systems, USA, içinde (ss. 975-984). doi: $10.1145 / 1518701.1518851$

Jacob, R. J., Girouard, A., Hirshfield, L. M., Horn, M. S., Shaer, O., Solovey, E. T., ve Zigelbaum, J. (2008). Reality-based interaction: a framework for post-WIMP interfaces. Proceedings of the SIGCHI Conference on Human factors in Computing Systems, Italy, içinde (ss. 201-210). doi: $10.1145 / 1357054.1357089$

Jadán-Guerrero, J., Guerrero, L., López, G., Cáliz, D. ve Bravo, J. (2015). Creating TUIs using RFID sensors- A case study based on the literacy process of children with down syndrome. Sensors, 15(7), 14845-14863.

Jadan-Guerrero, J., Jaen, J., Carpio, M. A. ve Guerrero, L. A. (2015). Kiteracy: A kit of tangible objects to strengthen literacy skills in children with down syndrome. Proceedings of the 14th International Conference on Interaction Design and Children, USA, içinde (ss. 315-318). doi: $10.1145 / 2771839.2771905$

Kara, N. (2015). Design, development and use of a smart toy for preschool children: A design and development research (Yayımlanmamış doktora tezi). Orta Doğu Teknik Üniversitesi, Ankara.

Keay-Bright, W. (2008). Tangible technologies as interactive play spaces for children with learning difficulties: the Reactive colours project. The International Journal of Technology, Knowledge and Society, 4(1), 111-120.

Linke, R., Kothe, T. ve Alt, F. (2017). TaBooGa: A hybrid learning app to support children's reading motivation. Proceedings of the 2017 Conference on Interaction Design and Children, USA, içinde (ss. 278-285). doi: 10.1145/3078072.3079712

Marco, J., Cerezo, E., Baldassarri, S., Mazzone, E. ve Read, J. C. (2009). Bringing tabletop technologies to kindergarten children. Proceedings of the 23rd British HCI Group Annual Conference on People and Computers: Celebrating People and Technology, UK, içinde (ss. 103-111). 
Marshall, P. (2007). Do tangible interfaces enhance learning? Proceedings of the 1st international conference on Tangible and embedded interaction, USA, içinde (ss. 163-170). doi: $10.1145 / 1226969.1227004$

MEB. (2008). Özel ĕgitim ve rehabilitasyon merkezi özel ögrenme güçlüğü destek eğitim programı. Ankara: T.C. Milli Eğitim Bakanllğı Özel Öğretim Kurumları Genel Müdürlüğü.

O'Malley, C. ve Fraser, D. S. (2004). Literature review in learning with tangible technologies (Rapor No. 12). Bristol: Futurelab.

Pandey, S. ve Srivastava, S. (2011a). SpellBound: a tangible spelling aid for the dyslexic child. Proceedings of the $3 \mathrm{rd}$ International Conference on Human Computer Interaction, India, içinde (ss. 101-104). doi: 10.1145/2407796.2407813

Pandey, S. ve Srivastava, S. (2011b). Tiblo: a tangible learning aid for children with dyslexia. Procedings of the Second Conference on Creativity and Innovation in Design, Netherlands, içinde (ss. 211-220). doi: 10.1145/2079216.2079247

Patton, M. (1990). Qualitative evaluation and research methods (2. Bask1). Thousand Oaks, CA: Sage Publications.

Patton, M. Q. (1999). Enhancing the quality and credibility of qualitative analysis. Health Services Research, 34(5-2), 1189-1208.

Shaer, O. ve Hornecker, E. (2010). Tangible user interfaces: past, present, and future directions. Foundations and Trends in Human-Computer Interaction, 3(1-2), 1-137.

Sitdhisanguan, K., Chotikakamthorn, N., Dechaboon, A. ve Out, P. (2012). Using tangible user interfaces in computer-based training systems for low-functioning autistic children. Personal and Ubiquitous Computing, 16(2), 143-155.

Starcic, A. I., Cotic, M. ve Zajc, M. (2013). Design-based research on the use of a tangible user interface for geometry teaching in an inclusive classroom. British Journal of Educational Technology, 44(5), 729-744.

Sucuoğlu, B. ve Kargın, T. (2006). İlköğretimde kaynaştırma uygulamaları. İstanbul: Morpa Kültür Yayınları.

Ullmer, B. ve Ishii, H. (2000). Emerging frameworks for tangible user interfaces. IBM Systems Journal, 39(3-4), 915-931.

Yıldırım, A. ve Şimşek, H. (2013). Sosyal bilimlerde nitel araştırma yöntemleri (9. Baskı). Ankara: Seçkin Yayıncılık.

Zuckerman, O., Arida, S. ve Resnick, M. (2005). Extending tangible interfaces for education: digital montessori-inspired manipulatives. Proceedings of the SIGCHI conference on Human factors in computing systems, USA, içinde (ss. 859-868). doi: 10.1145/1054972.1055093

\section{Extended Abstract}

\section{Introduction}

There are many students with specific learning disabilities (SLD) in education system who cannot perform academic tasks at expected level. It is a necessity to meet their needs. At this point, educational technology may have some potential to meet their needs. However, computer assisted materials may be insufficient to provide physical engagement and multi-sensory interaction. A tangible mobile application was developed for students with SLD by researchers in order to teach 6th grade cell concept. The main purpose of this study is to obtain the reflections of special education teachers after using the tangible mobile application by students with SLD. Tangible mobile application was used by two groups to determine whether it is easy to use or not.

\section{Method}

In this study, the qualitative data collection techniques were employed to obtain the reflections of special education teachers after using the tangible mobile application on students with SLD. Case study was used in the study. An implementation was conducted in order to examine the reflections of special education teachers after using the tangible mobile application on students with SLD. After a pilot study had been conducted with a special education teacher (SET1) and a student with SLD (FV) in 6th grade, the main study was held with a special education teacher (P1) and a student with SLD (MYP) in 6th grade. They were video-recorded. Semi-structured interviews were administered to two special 
education teachers to find out their experience and ideas on the use of tangible mobile application. Two special education teacher $(n=2)$ and students with SLD $(n=2)$ were selected as subjects. A semistructured interview was administered on three categories: 1) the process for starting use, 2) the process for use, and 3) future use. The semi-structured interview form consisted of eight questions. The questions focused on the process for starting use $(n=2)$, the process for use $(n=3)$, future use $(n=3)$. In addition, observation notes were taken about the use of tangible mobile application by researchers.

Teachers or students were not given any training or using manual before the implementations. Researchers gave tablets and objects to teachers. Researchers mentioned teachers that they should grasp the objects and then touched to the tablet screen. The video camera was placed to an appropriate point in order to keep records without any distraction. After the each implementation, a semi-structured interview conducted with two special education teacher. The pilot study took approximately 40 minutes to complete while the main study took 30 minutes to complete.

\section{Results}

Teachers' reflections were summarized below.

\section{Theme 1: The process for starting use}

First reactions and implications of all participant (two special education teachers (SET1, P1) and also students with SLD) were very positive and inquiring. All participants perceived the tangible mobile application as easy to use. One of the students with SLD (MYP) had some problems about touching objects to the screen. SET1 and his students confused about touching area at first. They thought they should touch the objects which were circle. Trial screen made learn to use easier.

\section{Theme 2: The process for use}

Both of special education teachers (SET1, P1) described the process of use mostly easy. The features of the tangible mobile application provide ease to use. All participant enjoyed of using it. SET1 and P1 perceived that these model facilities the use of application. SET1 thought the application helps teacher to be more ready and be prepared for class. P1 and SET1 emphasized using tangible mobile application can motivate the students with SLD. SET1 believed the interaction facilitates the child's learning. P1 stated the interaction was good. Transparent images of the objects which were presented on the screen before the students touch the objects were very useful and guiding. The tangible mobile application motivated MYP and allows him to continue until the end by arouse his curiosity. The guidance of P1 and SET1 was very professional. At the beginning of the tutorial part and at some of long instructions, FV showed some signs of boredom. SET1 showed signs of boredom when the student thought too much. SET1 suggested the session time should be shorter. SET1 emphasized that his students sometimes touched the objects randomly to the tablet screen. SET1 emphasized there were some touching problems while his student was using the tangible mobile application. P1 suggested that a user manual of the tangible mobile application makes it easier.

\section{Theme 3: Future use}

Both of special education teachers (SET1, P1) were very positive and willing to use of the tangible mobile applications their classes. They want to use the tangible mobile application for this subject and another subjects or another course like Math, Geometry, Language, Social Studies. They want to use the tangible mobile application because of its advantages.

\section{Discussion}

The findings of the current study indicated that first reactions and implications of the teachers and the students with SLD were very positive and inquiring. They were curious to follow up all the coming steps. The process for starting use was found to be satisfactory by the participants. The results also showed that the teachers and the students with SLD perceived the tangible mobile application as easy to use. However, they encountered few difficulties only at the first trial. The reason for the first time difficulty could be related to teachers' inexperience and unfamiliarity with the system. Although there was not a major usability issue, touching problems have been observed in students with SLD. In order to overcome this problem, a small introductory text with images or a video can be prepared. Thus, teachers can learn these little points and can guide their students more correctly. Furthermore, the current 
study revealed that all participants enjoyed using the tangible system. All participants were motivated while they were using the application.

The results revealed that all participants liked the tangible interaction. The teachers thought that it can facilitate students' learning. Moreover, the teachers stated that the tangible mobile application can help students to learn permanently because of multi-sensory interaction.

Finally, the teachers wanted to use such materials in the future. They were very positive and willing to use of the tangible mobile applications in their classes. In addition, they can use it in other subjects and lessons. Literature review supports the findings of this study. 